\title{
A Comparison of Voice Activity and Participation Profiles according to the Patterns of Professional Voice Use
}

\author{
Seung Jin Lee ${ }^{\mathrm{a}, \mathrm{b}}$, Sung-Eun Lim ${ }^{\mathrm{c}}$, Hong-Shik Choi ${ }^{\mathrm{b}, \mathrm{d}}$, Jae-Yol Lim ${ }^{\mathrm{a}, \mathrm{b}}$ \\ ${ }^{a}$ Department of Otorhinolaryngology, Yonsei University College of Medicine, Seoul, Korea \\ ${ }^{b}$ The Institute of Logopedics and Phoniatrics, Department of Otorhinolaryngology, Gangnam Severance Hospital, Seoul, Korea \\ ${ }^{c}$ Voice Clinic, Department of Otorhinolaryngology, Gangnam Severance Hospital, Seoul, Korea \\ ${ }^{d}$ Hana ENT Hospital, Seoul, Korea
}

\author{
Correspondence: Jae-Yol Lim, MD, PhD \\ Department of Otorhinolaryngology, Gangnam \\ Severance Hospital, Yonsei University College of \\ Medicine, 211 Eonju-ro, Gangnam-gu, Seoul 06273, \\ Korea \\ Tel: $+82-2-2019-3468$ \\ Fax: +82-2-3463-4750 \\ E-mail: jylimmd@yuhs.ac
}

Received: July 11, 2019

Revised: July 24, 2019

Accepted: July 24, 2019

This work was supported by the Ministry of Education of the Republic of Korea and the National Research Foundation of Korea (No. NRF-2018S1A5A2A02069988).

\begin{abstract}
Objectives: The present study sought to investigate whether voice activity and participation profiles differ according to the patterns of professional voice use upon controlling for presence of benign vocal fold lesions (BVFL), gender, and severity of voice disorders. Methods: A total of 120 patients with BVFL and 120 normal controls were recruited for this study. Each participant was divided into four groups (30 participants for each group) according to the levels of professional voice use: elite vocal performer (group I), professional voice user (group II), non-vocal professional (group III), and non-vocal non-professional (group IV). The Korean version of the Voice Activity and Participation Profile (K-VAPP) and the GRBAS scale were performed. A multiple regression analysis was performed to predict each $\mathrm{K}$ VAPP subscale score. Results: Upon controlling for presence of BVFL, gender, and severity, group I showed higher score in the job subsection $(\beta=8.231, p<.001)$, whereas group II showed higher scores in the total score $(\beta=26.647, p=.002)$, activity limitation score ( $\beta=9.639, p=.002)$, participation restriction score $(\beta=11.376, p=.001)$, and subsections of job $(\beta=7.124, p<.001)$ and social communication $(\beta=4.553, p=.001)$ compared to the reference group (IV). On the contrary, group III did not show difference compared to the reference group. Conclusion: The current results indicated that subjective voice complaint of professional voice users is not less than that of elite vocal performers. Further research pertaining to more detailed profiles of various professions is needed.
\end{abstract}

Keywords: Voice Activity and Participation Profile, Professional voice use, Patient-reported outcome measures, ICF, Voice disorders
음성장애가 한 개인에게 미치는 영향은 후두검사를 통해 관찰 되는 비정상적 소견 혹은 대화 상대방이 듣게 되는 음질 문제에 국 한되지 않는 그 이상의 문제이며, 삶의 질을 현저히 저하시킨다(Ma \& Yiu, 2011; Ruotsalainen, Sellman, Lehto, Jauhiainen, \& Verbeek, 2007). 개인의 삶을 구성하는 요소 가운데 큰 비중을 차지하는 것 으로는 직업이 있으며, 다른 직업에 비해 직무상 음성을 많이 사용 함과 동시에 음성 문제가 있을 때 직무 수행이나 삶의 질에 더욱 큰 영향을 받을 수 있는 직업들이 존재한다. 가수나 배우뿐만 아니라, 교강사, 콜센터 직원 등을 포함하는 넓은 의미의 직업적 음성사용 자(occupational voice user 혹은 professional voice user)는 무려 전 체 직업군의 $25 \%-35 \%$ 에 이르며, 이와 같은 직업적 음성사용자에서 더욱 높은 음성장애 발생비율과 주관적 음성장애가 보고된다는 점은 그다지 놀랄 만한 일이 아니다(Cantor Cutiva \& Burdorf, 2014; Choi, Lim, \& Kim, 2013; Dragone, 2011; Kim, 2015; Piwowarczyk, Oliveira, Lourenço, \& Behlau, 2012; Zambon, Moreti, \& Behlau, 2014).

널리 인용되는 직업적 음성사용 수준에 따른 분류(Kim, 2015; Koufman \& Isaacson, 1991)를 살펴보면, 직업적인 음성의 수요(de- 
mands)와 음성사용량(vocal load)에 따라 크게 다음과 같은 네 가 지의 수준으로 구분할 수 있다. 즉 집단 I: 엘리트 음성사용자(elite vocal performer: 가수, 배우, 방송인 등), 집단 II: 직업적 음성사용 자(professional voice user: 교강사, 목사, 상담자, 콜센터 상담원 등), 집단 III: 직업적 비음성사용자(non-vocal professional: 의사, 변호사, 사업가 등), 집단 IV: 비직업적 비음성사용자(non-vocal non-professional: 사무직, 주부 등)로 나눌 수 있다. 엘리트 음성사 용자는 음성에 약간의 이상만 생겨도 심각한 결과를 얻을 수 있는 사람인 데 비해, 직업적 음성사용자는 중간 정도의 음성 문제가 있 을 때 직무 수행을 적절히 하지 못할 수 있는 사람이다. 한편 직업적 비음성사용자는 심각한 음성 문제가 있을 때에야 비로소 적절한 직무 수행을 하지 못할 수도 있는 사람이며, 비직업적 비음성사용 자는 음성의 질이 적절한 직무 수행에 필수 조건이 아닌 사람을 말 한다. 개별 직업마다 음성사용량에 따른 차이 또한 목소리 문제에 영향을 미치는 중요한 변인으로 생각되나, 본 연구에서는 선행연구 에서 많이 언급되는 위와 같은 직군 분류를 이용하여 집단별 비교 를 정밀하게 수행하고, 후속연구에서는 개별 직군에서 나타나는 음성사용량에 따른 차이를 확인하여 보고자 한다.

직업적 음성사용자에 있어 음성장애가 많이 발생하게 되는 가장 큰 위험 요인 가운데 하나는 바로 음성의 오용(misuse)과 남용(abuse) 이다. 이러한 음성의 오남용은 흔히 성대 결절(vocal nodule)이나 폴 립(vocal polyp)과 같은 양성 성대점막질환(benign vocal fold lesion, BVFL)을 유발한다. BVFL은 악성 종양과 구분되며, 후두의 구조에 변화가 생긴 음성 질환을 포괄하는 용어로 결절이나 폴립 외에도 성대내 낭종(intracordal cyst) 또는 가성낭종(pseudocyst), 라인케 부종(Reinke's edema), 육아종(granuloma), 성대구증(sulcus vocalis), 과각화증(hyperkeratosis), 섬유성 종괴(fibrous mass), 반응성 성대병변(reactive vocal fold lesion) 등을 포함한다(Byeon \& Lee, 2010; Kwon \& Kim, 2015). 특히 국민건강영양조사 자료를 활용한 한 선행연구(Byeon \& Lee, 2010)는 단순노무직인 사람은 여타 직업군에 비해 BVFL을 갖게 될 가능성이 $60 \%$ 더 낮다고 보 고하였다(odds ratio $=0.40 ; 95 \%$ confidence interval, 0.21-0.75). 이 는 비직업적 비음성사용자의 경우이므로 직업적 음성사용 여부가 BVFL의 발생 위험 요인에 해당할 수 있는 가능성을 시사하는 결과 인 것으로 여겨진다.

어떠한 질환에 의한 것이든 음성장애에 대한 평가는 다면적이고 도 종합적인 것이어야만 하며, 직업적 음성사용자의 경우 일반인에 비해 더욱 면밀하고 상세한 검사가 이루어져야만 한다(Ma \& Yiu, 2006, 2011). 이를 위하여, 심리측정적 평가(psychometric assessment), 음향학적 분석(acoustic analysis), 전기성문파형검사(elec- troglottography), 청지각적 평가(auditory-perceptual evaluation), 후두 스트로보스코피(laryngeal stroboscopy) 등의 형태학적 평가, 공기역학적 평가(aerodynamic assessment) 등 다양한 양태의 검사 들이 숙련된 전문가에 의해 상호보완적으로 이루어지는 것이 바람 직하며, 많은 음성클리닉에서 실제로 이와 같은 다면적, 다학제적 평가가 이루어지도록 하기 위해 노력을 기울이고 있다(Boone, McFarlane, Von Berg, \& Zraick, 2014; Choi, 2013).

이 중 심리측정적 평가 양식에 해당되는 자기보고식 설문검사들 은 비교적 검사의 시행 및 해석방법이 간단하다는 장점이 있으며, 무엇보다도 환자 개개인의 특성이 반영되므로, 여타 객관적 검사도 구들을 통해서도 감지할 수 없는 세밀한 진전 사항을 탐지할 수 있 다는 점에서 음성장애의 치료에 중대한 시사점들을 제공한다고 할 수 있다. 여러 설문검사 도구들 중에서 세계보건기구(World Health Organization, WHO)에 의해 1980년 만들어진 International Classification of Impairments, Disabilities and Handicaps (ICIDH)의 틀에 입각하여 음성장애의 손상, 기능 제약, 사회적 핸디캡 측면을 살펴보는 자기보고식 심리측정적 평가도구로서 음성장애지수 (Voice Handicap Index, VHI)가 전 세계적으로 널리 이용되어 오 고 있으며, 두 가지의 한국어판으로 번안되어 현재 우리나라 대부 분의 이비인후과 음성클리닉 임상현장에서 활발하게 이용되고 있 다(Yun, Kim, Son, \& Choi, 2008; Kim et al., 2007). 그러나 VHI의 경우 음성장애 때문에 일상적인 활동에서 받는 제한(activity limitation)과 그 활동에 실제로 참여하는 데 대한 제약(participation restriction)이 분리되어 있지 않다는 한계를 지니고 있다. 그리고 무 엇보다도, 직업과 관련된 설문 항목이 거의 없어 직업적 음성사용 에 따른 차이를 살펴보기에 다소 어려움이 있을 수 있다. 삶의 질에 대한 평가도구로 번안된 한국어판 음성관련 삶의 질(Korean version of Voice-related Quality of Life; Kim et al., 2007) 설문지 또한 유사한 문제점을 지니고 있어 임상 및 연구에서의 의의에 다소의 제한이 있는 실정이다.

이와 같은 한계를 극복할 수 있는 관점으로 2001년 WHO에 의 해 다시금 제안된 국제 기능장애건강분류(International Classification of Functioning, Disabilities, and Health, ICF)가 있다. 이 틀 은 건강 관련 문제를 신체 기능, 신체 구조, 활동 및 참여, 맥락 요인 으로 구분하며, 환자 개개인의 특성이 반영된 관점이라는 점에서 의사소통장애의 여러 영역에서도 임상과 연구에 활발하게 적용되 어 오고 있다(Eadie, 2003). 음성장애의 관점에서 살펴보면, 음성 활동 제한은 '음성을 이용한 활동에 가해지는 제한’이며, 활동 제한 은 '실제 음성을 이용한 활동을 줄이거나 피하는 것'을 의미한다. 이 러한 ICF의 틀을 적용하여 개발된 설문검사 도구는 음성장애 영역 
에서는 현재까지는 음성 활동 및 참여 프로파일(Voice Activity and Participation Profile, VAPP; Ma \& Yiu, 2001)이 유일하다. VAPP는 음성 활동 및 참여 프로파일-한국판(Korean version of the Voice Activity and Participation Profile, K-VAPP)으로 번안 및 표준화되 어 절단점 및 백분위 점수가 제시되었다(Lee et al., 2016). 아울러 엑 셀시트를 이용하여 특정 환자의 음성 활동과 참여에 대한 프로파 일 측정 결과를 음성장애 환자의 병인집단에 따른 측정치들과 비 교하여 용이하게 시각화할 수도 있다(Lee, Choi, \& Kim, 2019). 이 러한 시각화는 중재 방향에 대한 임상적 시사점을 제공함으로써 음성장애 환자에게 적절한 환자맞춤형 중재접근법을 모색하는 데 기초자료로 활용될 수 있다. 또한 수술적 중재 전후의 반응도 또한 검증되어 해외 선행연구와 마찬가지로 양호한 반응도를 보이는 것 으로 보고되었으므로(Kleemola, Helminen, Rorarius, Sihvo, \& Isotalo, 2011; Lee, Lim, \& Choi, 2017), 직업적 음성사용 수준에 따 른 주관적 음성장애 정도를 $\mathrm{ICF}$ 의 틀에 의거하여 살펴보기에 적합 하다고 할 수 있다.

직업적 음성사용과 관련하여 유사한 정도의 음성장애를 가진 환자라 하더라도 직업적 음성사용자가 더욱 큰 불편감을 호소한다 는 점은 주목할 만하다(Kim, 2015). 이러한 경향은 가수와 같은 엘 리트 음성사용자 이외에도 콜센터 상담원(Piwowarczyk et al., 2012), 스포츠강사(Fontan, Fraval, Michon, Déjean, \& Welby-Gieusse, 2017), 교사 혹은 교직원(Bassi et al., 2011; Cantor Cutiva \& Burdorf, 2014; Dragone, 2011; Lyberg-Åhlander, Rydell, \& Löfqvist, 2012; Martinello, Lauris, \& Brasolotto, 2011; Natour, Sartawi, Al Muhairy, Efthymiou, \& Marie, 2016; Zambon et al., 2014), 심지어 교사(Meulenbroek, Thomas, Kooijman, \& de Jong, 2010; Thomas, Kooijman, Donders, Cremers, \& de Jong, 2007)나 언어재활사(Van Lierde et al., 2010)가 되고자 하는 학생에서도 나타나는 것으로 보 고되어 왔으며, 상담가, 언어재활사, 영업직, 창구직원 등과 같이 음 성사용량이 많은 직업적 음성사용 직업군에서 보고되는 결과이다 (Dassie-Leite, Delazeri, Baldissarelli, \& Weber, 2014). 보다 중대한 문제는 이러한 넓은 의미의 모든 직업적 음성사용자에서 음성 문 제가 직무에 미치는 영향으로 인해 실직을 유발하거나 실질적인 수 입의 감소로 직결되는 경우가 매우 빈번하다는 점이다(Choi et al., 2013; Dassie-Leite et al., 2014; Ruotsalainen et al., 2007). 따라서 음 성언어의학적인 관점을 토대로 직업적 음성사용자에 특화된 음성 평가 시스템의 수요 및 필요성이 증대되고 있다.

그러나 현실적으로 효과적인 조기 중재를 위한 프로그램의 부재 로 인하여 각 기관에 따라 서로 다른 평가와 중재가 이루어지는 경 향이 있으며, 결국 이로 인한 사회적 비용의 증가가 야기되고 있는
실정이다. 예컨대 교사의 경우만을 살펴보더라도 이러한 경향은 명 확하다. 국내의 경우 명확히 수치가 보고된 연구를 찾기 어려우나, 미국 플로리다의 공립학교 교사들을 대상으로 한 선행연구에 따르 면, 최근 1 주일간 목소리 문제로 수업을 하지 못한 교사의 비율이 $8.23 \%$ 에 달하였고, 목소리 문제와 관련하여 결근으로 인한 연간 손실 비용이 약 1 백만 달러, 출근한 상태에서 생산성 저하로 인한 연간 손실 비용이 약 1 천 2 백만 달러로 추산된다고 하였다(Rosow et al., 2016). 또 다른 선행연구에서는 음성장애로 인한 미국 내 교 사들의 실직으로 인한 비용 및 치료 비용이 연간 약 25 억 달러로까 지 추산된다고 하였다(Verdolini \& Ramig, 2001). 이러한 자료는 물론 '교사'라는 직종에 국한된 자료라는 점에서 실제 전체 직업적 음성사용자가 떠안게 되는 경제적 손해는 더욱 클 것이라 예상할 수 있다. 따라서 이들 직업적 음성사용자들의 직업적 음성사용 수 준에 따른 주관적 음성장애 정도에 대한 보다 면밀하고 특화된 연 구자료가 구축되는 것이 매우 시급하며, 이를 위한 기초연구들이 요구되고 있는 시점이라 할 수 있다. 이러한 기초연구는 나아가 직 업적 음성사용자의 근거기반 중재에 일조할 수도 있을 것으로 여겨 진다.

다만 직업적 음성사용 수준에 따른 음성 활동 및 참여 프로파일 비교를 수행할 때, 직업적 음성사용 수준의 순수한 영향을 파악하 고자 한다면 대상자의 주관적 음성장애 정도에 영향을 미칠 수 있 는 다른 요인들을 적절히 통제하여야만 할 것이다. 이러한 요인들로 는 예컨대 음성장애의 중증도, 성별, 음성 질환 여부 등을 들 수 있 다. 먼저 다양한 종류의 음성 질환을 가진 환자군이거나 음성장애 의 중증도가 높을수록 더 큰 정도의 주관적 음성장애를 보고한다 는 점은 놀랄만한 일은 아니다(Kim et al., 2007; Lee et al., 2016; Lee, Lim, Lim, \& Choi, 2018). 그런데 한 선행연구(Lee et al., 2018) 에서는 연령이 증가할수록 K-VAPP의 활동제한점수(activity limitation score, ALS), 참여제약점수(participation restriction score, $\mathrm{PRS}$ ), 직업영역점수가 감소하는 것으로 보고되어 연령에 따른 $\mathrm{K}-$ VAPP 점수 차이의 가능성을 시사하였다. 또한 다른 연구(DassiLeite et al., 2014)는 음성장애가 없는 정상인에서 여성(360명)의

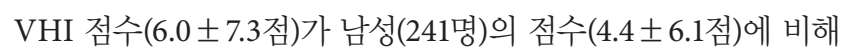
유의하게 더 높았다고 보고하여 성별 차가 존재할 가능성을 시사 하였다. 따라서 이와 같은 요인들이 적절하게 고려되어야 실제 직업 적 음성사용 수준이 순수하게 미치는 영향 정도를 적절히 파악할 수 있을 것이다.

따라서 본 연구에서는 음성장애의 중증도와 성별, BVFL 여부를 통제하였을 때, 직업적 음성사용 수준에 따라 음성 활동 및 참여 프로파일 점수에 차이가 있는지의 여부를 알아보고자 하였다. 구 
체적으로는 다른 요인을 통제하였을 때 기준 집단인 비직업적 비음 성사용자(집단 IV)에 비해 엘리트 음성사용자(집단 I), 직업적 음성 사용자(집단 II), 직업적 비음성사용자(집단 III)의 음성 활동 및 참 여 프로파일 점수의 차이가 나는지를 알아보고자 하였다.

\section{연구방법}

\section{연구대상}

$\mathrm{G}^{\star}$ Power (Faul, Erdfelder, Buchner, \& Lang, 2009)를 이용하여 6 개의 예측변인을 가지고 다중회귀분석을 수행하기 위한 최소한의 표본수를 계산하였을 때, 전체 표본수가 215명으로 산정되었다(effect size $\mathrm{f}^{2}=.1$, Power $\left.=.95\right)$. 따라서 연구의 대상은 BVFL로 진단된 환자군 120 명과 정상 대조군 120 명으로 하였다. 각 집단은 음성사 용 수준에 따라 엘리트 음성사용자(집단 I), 직업적 음성사용자(집 단 II), 직업적 비음성사용자(집단 III), 비직업적 비음성사용자(집단 IV) 각 30 명(남녀 각 15 명)으로 구성되었다. 음성사용 수준에 따른 연령(평균 \pm 표준편차)은 집단 I이 $30.88 \pm 12.03$ 세, 집단 II가 32.28 \pm 12.03 세, 집단 III이 $32.53 \pm 8.28$ 세, 집단 IV가 $34.35 \pm 11.85$ 세였
으며, 음성사용 수준별 집단에 따른 연령 차이는 없었다 $(F=1.203$, $p=.309$ ).

서론에서 상세히 기술한 직업적 음성사용 수준에 따른 각 집단 별 직업 분포는 Figure 1에 제시되어 있다. 가장 많은 비중을 차지한 직업을 살펴보면, 집단 I은 실용음악 가수 혹은 실용음악전공 학생 (58\%)과 성악가 혹은 성악전공 학생(32\%)이었고, 집단 II는 교사 (27\%)와 언어재활사(27\%), 집단 III은 사무직(72\%)과 의사(11\%)였 으며, 집단 IV는 대학생(37\%)과주부(23\%)였다.

환자군은 본원 음성클리닉에 내원하여 1 인의 후두전문의에 의 해 BVFL로 진단된 120명의 환자로 남성 60명(31.31 18.74 세)과 여 성 60 명(38.72 \pm 11.15 세)이었다. 내원 전 타기관에서 수술적 혹은 행동적 치료를 받은 이력이 있거나, 문맹 또는 무학이거나, 시력 문 제를 호소한 경우 대상자에서 제외하였다. 환자의 진단명은 편측 성대폴립(40.8\%), 양측 성대결절(25.8\%), 편측 성대내 낭종(11.7\%), 성대구증( $11.7 \%)$, 접촉성 육아종 $(4.2 \%)$, 성대 반흔(0.8\%) 순이었다.

대조군은 서울 및 경기지역 거주 중인 대상자로 환자군과 성별 및 연령(3세 이내)을 일치시켰으며, 최근 10 년 이내 흡연력이 있는 경우, 문맹이나 무학인 경우, 시력 문제를 호소한 경우, 그리고 유의
Group I

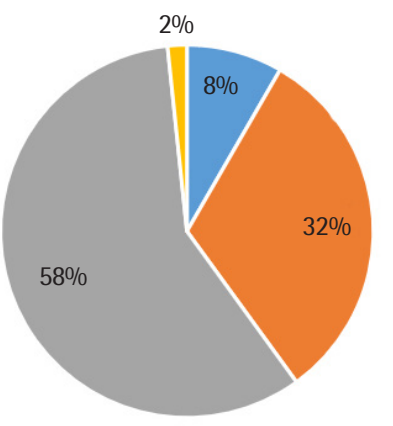

- Actor

- Classical singer or student

- Contemporary commercial singer or student

- Voice actor
Group III

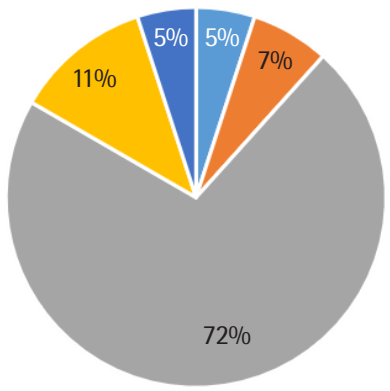

Group II

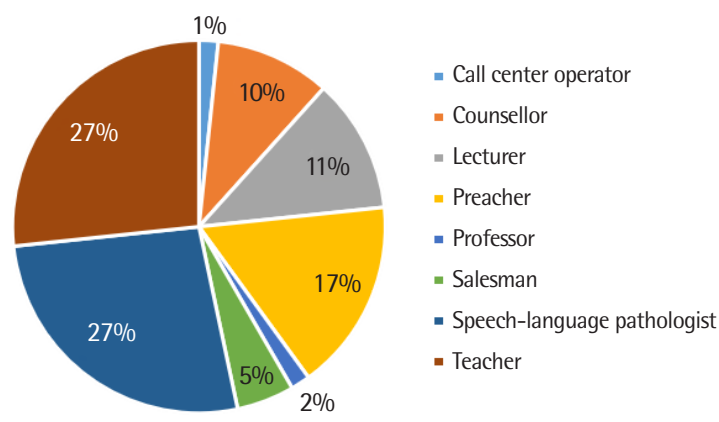

Group IV

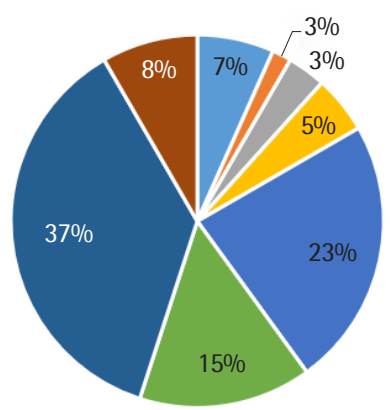

- Clerk

- Cook

- Driver

- Graduate student

- Housewife

- Laborer

- Undergraduate student

- Unemployed

Figure 1. Job distribution of the participants according to the levels of professional voice use.

Group I = elite vocal performer group; group II = professional voice user group; group III= non-vocal professional group; group IV= non-vocal non-professional group. 
미한 주관적 음성장애가 있는 경우 제외하였다. 주관적 음성장애 정도의 기준은 K-VAPP 총점이 14.5점 이상이거나, GRBAS 척도 (Hirano, 1981)의 Grade 척도에서 1점 이상으로 평정된 경우를 기 준으로 하였다(Lee et al., 2016).

\section{연구절차}

각 대상자에 대하여 심리측정적 평가로는 K-VAPP를 시행하되, 대상자마다 느끼는 불편감이 다를 수 있다는 사실을 주지시키고 11점 척도에 의한 평정 방법을 간략히 설명함으로써 성실한 설문 응답을 유도하였다(Lee et al., 2017). 청지각 평가로는 표준문단인 '가을' $(\mathrm{Kim}, 2012)$ 문단을 자연스러운 음높이와 크기로 전부 읽도 록 하였으며, 이를 제 1 저자(언어병리학박사, 1 급 언어재활사, 음성 장애 분야종사 경력 8 년)와 제 2 저자(언어병리학석사, 1 급 언어재활 사, 이비인후과 음성장애 분야 종사 경력 21년)가 현장에서 듣고 GRBAS 척도를 이용하여 전반적 중증도(grade, $\mathrm{G})$ 에 대하여 합치 에 이르도록 평가하였다(Lee et al., 2018). 구체적인 척도로는 0은 정상, 1 은 약함(mild), 2 는 중간(moderate), 3 은 심함(severe)으로 평 정하여 기록하였다. 이때 전반적 중증도에 대한 기존의 3점 척도를 유지하면서도 보다 상세하고 세밀화된 평가를 수행하기 위하여, 각 척도 사이의 중간 단계를 설정하였다(Lee et al., 2017). 즉 0.5 는 정상약함, 1.5 는 약함-중간, 2.5 는 중간-심함으로 설정하여 평정하였다.

\section{자료분석}

먼저 K-VAPP의 경우 총점(total score, TTL; 최고 280점), ALS (100점), PRS (100점)를 계산하였고, 각 하위영역별 점수를 다음과 같이 계산하였다. 하위영역 1 은 목소리 문제의 심각한 정도에 대한
본인의 인식(Severity)으로 1개 문항, 0-10점 배점이었고, 하위영역 2 는 직업에 대한 영향 $(\mathrm{Job})$ 으로 4 개 문항, 0-40점 배점이었다. 하위 영역3은 일상 의사소통에 대한 영향(Daily)으로 12개 문항, 0-120 점 배점이었으며, 하위영역4는 사회적 의사소통에 대한 영향(Social)으로 직업과 마찬가지로 4개 문항, 0-40점 배점이었다. 마지막 으로 하위영역5는 본인의 감정에 대한 영향(Emotion)으로 7 개 문 항, 0-70점 배점이었다.

\section{통계분석}

TTL, ALS, PRS 및 5 개의 하위영역 점수를 종속변수로 하여 다 중회귀분석(multiple regression analysis)을 수행하였다. 독립변수 는 총 6 개였으며, BVFL 여부에 따른 집단, 성별, G, 그리고 직업적 음성사용 수준에 따른 집단 IV를 기준 집단으로 하여 집단 I, II, III

Table 2. Summary of the regression models predicting the K-VAPP subscale scores of three professional groups

\begin{tabular}{lcccccc}
\hline K-VAPP score & $\mathrm{R}$ & $\mathrm{R}^{2}$ & $\Delta \mathrm{R}^{2}$ & $\Delta F$ & $\mathrm{df}$ & $p$-value \\
\hline TTL & 0.746 & 0.557 & 0.557 & 48.829 & 6,233 & $<.001^{* * *}$ \\
ALS & 0.725 & 0.526 & 0.526 & 43.046 & 6,233 & $<.001^{* * *}$ \\
PRS & 0.661 & 0.436 & 0.436 & 30.074 & 6,233 & $<.001^{* * *}$ \\
Severity & 0.852 & 0.726 & 0.726 & 102.95 & 6,233 & $<.001^{* * *}$ \\
Job & 0.743 & 0.552 & 0.552 & 47.878 & 6,233 & $<.001^{* * *}$ \\
Daily & 0.668 & 0.432 & 0.432 & 31.285 & 6,233 & $<.001^{* * *}$ \\
Social & 0.623 & 0.388 & 0.388 & 24.603 & 6,233 & $<.001^{* * *}$ \\
Emotion & 0.729 & 0.531 & 0.531 & 44.032 & 6,233 & $<.001^{* * *}$ \\
\hline
\end{tabular}

K-VAPP $=$ Korean version of the Voice Activity and Participation Profile; $T T L=$ total score of the K-VAPP; $A L S=$ activity limitation score; $P R S=$ participation restriction score.

${ }^{* * *} p<.001$

Table 1. Descriptive statistics of the K-VAPP subscale scores and G score of the GRBAS scale

\begin{tabular}{|c|c|c|c|c|c|c|c|c|}
\hline \multirow{2}{*}{ Parameters } & \multicolumn{4}{|c|}{ Patient ( $N=120)$} & \multicolumn{4}{|c|}{ Control $(\mathrm{N}=120)$} \\
\hline & Group I & Group II & Group III & Group IV & Group I & Group II & Group III & Group IV \\
\hline$T T \mathrm{TL}$ & $108.13(57.62)$ & $127.20(74.28)$ & $82.13(64.90)$ & $80.87(71.58)$ & $6.87(11.11)$ & $3.00(3.81)$ & $2.77(5.08)$ & $1.53(2.08)$ \\
\hline ALS & $31.57(21.02)$ & $43.53(26.10)$ & $30.87(24.40)$ & $27.40(27.75)$ & $2.93(5.26)$ & $0.77(1.38)$ & $1.20(2.09)$ & $0.53(0.97)$ \\
\hline PRS & $36.13(26.20)$ & 43.17 (32.61) & 20.77 (23.32) & 22.63 (25.98) & 1.50 (3.93) & $1.07(2.59)$ & $0.10(0.40$ & $0.33(0.84)$ \\
\hline Severity & $6.60(2.24)$ & $7.00(2.30)$ & $5.77(3.16)$ & $6.33(2.67)$ & $1.20(1.56)$ & $0.40(0.72)$ & $0.37(0.76)$ & $0.17(0.46)$ \\
\hline Job & $23.27(10.10)$ & $23.77(10.47)$ & $10.10(9.16)$ & $10.27(12.28)$ & 3.07 (6.22) & $0.40(1.33)$ & $0.17(0.91)$ & $0.23(0.68)$ \\
\hline Daily & $33.37(29.47)$ & 47.00 (36.68) & $33.73(30.90)$ & $32.10(32.70)$ & $1.20(2.72)$ & $1.20(2.35)$ & 1.10 (2.04) & 0.60 (1.07) \\
\hline Social & $11.07(10.55)$ & $15.93(13.00)$ & $7.80(8.93)$ & 7.67 (10.98) & $0.17(0.75)$ & $0.23(0.77)$ & $0.20(0.48)$ & $0.03(0.18)$ \\
\hline Emotion & $33.83(17.53)$ & 33.50 (20.43) & $24.73(21.05)$ & $24.50(20.07)$ & $1.23(2.24)$ & $0.73(1.84)$ & 1.13 (3.56) & 0.50 (1.14) \\
\hline G & $1.80(0.47)$ & $2.03(0.60)$ & $2.25(0.60)$ & $2.32(0.53)$ & $0.33(0.24)$ & $0.12(0.22)$ & $0.10(0.20)$ & $0.07(0.17)$ \\
\hline
\end{tabular}

Values are presented as mean (SD).

K-VAPP= Korean version of the Voice Activity and Participation Profile; group I= elite vocal performer group; group II= professional voice user group; group III=non-vocal professional group; group IV= non-vocal non-professional group; $T \mathrm{~L}=$ total score of the K-VAPP; $A L S=$ activity limitation score; $P R S=$ participation restriction score; $G=G r a d e$ of the GRBAS scale. 
을 더미 변수로 코딩하여 분석하였다. 이때 동일한 회귀분석을 8 회 반복시행하였으므로, 제1종오류 감소를 위하여 결과에 대한 해석 시 본페로니 교정(Bonferroni correction)을 적용하여 유의수준은
$.00625(0.05 \div 8)$ 로 설정하였다. 통계분석에는 IBM SPSS statistics version 25.0 (IBM-SPSS Inc., Armonk, NY, USA) 프로그램을 이용 하였다.

Table 3. Coefficients of regression models predicting the K-VAPP subscale scores of three professional groups

\begin{tabular}{|c|c|c|c|c|c|c|}
\hline K-VAPP score & BVFL & Gender & Grade & Group I & Group II & Group III \\
\hline \multicolumn{7}{|l|}{$\overline{T T L}$} \\
\hline B & 45.506 & 16.473 & 25.901 & 19.260 & 26.647 & 1.407 \\
\hline SE & 14.657 & 6.019 & 6.878 & 8.510 & 8.504 & 8.466 \\
\hline$\beta$ & 0.332 & 0.120 & 0.403 & 0.122 & 0.168 & 0.009 \\
\hline$p$-value & $0.002^{*}$ & 0.007 & $<0.001^{* * *}$ & 0.025 & $0.002^{*}$ & 0.868 \\
\hline \multicolumn{7}{|l|}{ ALS } \\
\hline B & 6.471 & 4.291 & 13.093 & 4.848 & 9.639 & 2.213 \\
\hline SE & 5.320 & 2.185 & 2.497 & 3.089 & 3.087 & 3.073 \\
\hline$\beta$ & 0.134 & 0.089 & 0.581 & 0.087 & 0.173 & 0.040 \\
\hline$p$-value & 0.225 & 0.051 & $<0.001^{* * *}$ & 0.118 & $0.002^{*}$ & 0.472 \\
\hline \multicolumn{7}{|l|}{ PRS } \\
\hline B & 15.433 & 7.360 & 7.416 & 8.138 & 11.376 & -1.049 \\
\hline SE & 6.041 & 2.481 & 2.835 & 3.507 & 3.505 & 3.489 \\
\hline$\beta$ & 0.308 & 0.147 & 0.316 & 0.140 & 0.196 & -0.018 \\
\hline$p$-value & 0.011 & $0.003^{*}$ & 0.009 & 0.021 & $0.001^{*}$ & 0.764 \\
\hline \multicolumn{7}{|l|}{ Severity } \\
\hline B & 3.378 & 0.379 & 1.290 & 0.805 & 0.594 & -0.168 \\
\hline SE & 0.597 & 0.245 & 0.280 & 0.346 & 0.346 & 0.345 \\
\hline$\beta$ & 0.475 & 0.053 & 0.388 & 0.098 & 0.072 & -0.020 \\
\hline$p$-value & $<0.001^{* * *}$ & 0.123 & $<0.001^{* * *}$ & 0.021 & 0.087 & 0.626 \\
\hline \multicolumn{7}{|l|}{ Job } \\
\hline B & 10.395 & 2.233 & 2.811 & 8.231 & 7.124 & -0.107 \\
\hline SE & 2.586 & 1.062 & 1.214 & 1.501 & 1.500 & 1.494 \\
\hline$\beta$ & 0.432 & 0.093 & 0.249 & 0.296 & 0.256 & -0.004 \\
\hline$p$-value & $<0.001^{* * *}$ & 0.037 & 0.021 & $<0.001^{* * *}$ & $<0.001^{* * *}$ & 0.943 \\
\hline \multicolumn{7}{|l|}{ Daily } \\
\hline B & 7.317 & 6.101 & 14.471 & 2.640 & 9.337 & 1.206 \\
\hline SE & 6.954 & 2.856 & 3.264 & 4.038 & 4.035 & 4.017 \\
\hline$\beta$ & 0.126 & 0.105 & 0.531 & 0.039 & 0.139 & 0.018 \\
\hline$p$-value & 0.294 & 0.034 & $<0.001^{* * *}$ & 0.514 & 0.022 & 0.764 \\
\hline \multicolumn{7}{|l|}{ Social } \\
\hline B & 4.184 & 3.277 & 3.210 & 2.113 & 4.553 & 0.149 \\
\hline SE & 2.398 & 0.985 & 1.125 & 1.392 & 1.391 & 1.385 \\
\hline$\beta$ & 0.219 & 0.172 & 0.359 & 0.096 & 0.206 & 0.007 \\
\hline$p$-value & 0.082 & $0.001^{*}$ & $0.005^{*}$ & 0.130 & $0.001^{*}$ & 0.914 \\
\hline \multicolumn{7}{|l|}{ Emotion } \\
\hline B & 20.228 & 4.443 & 4.099 & 5.472 & 5.021 & 0.428 \\
\hline SE & 4.405 & 1.809 & 2.067 & 2.558 & 2.556 & 2.544 \\
\hline$\beta$ & 0.504 & 0.111 & 0.218 & 0.118 & 0.108 & 0.009 \\
\hline$p$-value & $<0.001^{* * *}$ & 0.015 & 0.049 & 0.033 & 0.051 & 0.867 \\
\hline
\end{tabular}

$\mathrm{BVFL}=$ presence of benign vocal fold lesions; K-VAPP=Korean version of the Voice Activity and Participation Profile; group I= elite vocal performer group; group II= professional voice user group; group III= non-vocal professional group; $T \mathrm{TL}=$ total score of the K-VAPP; $\mathrm{ALS}=$ activity limitation score; $\mathrm{PRS}=$ participation restriction score; $\mathrm{G}=\mathrm{Grade}$ of the GRBAS scale; $B=$ unstandardized regression coefficient; $\beta=$ standardized regression coefficient.

${ }^{*} p<.00625,{ }^{* * *} p<.001$. 


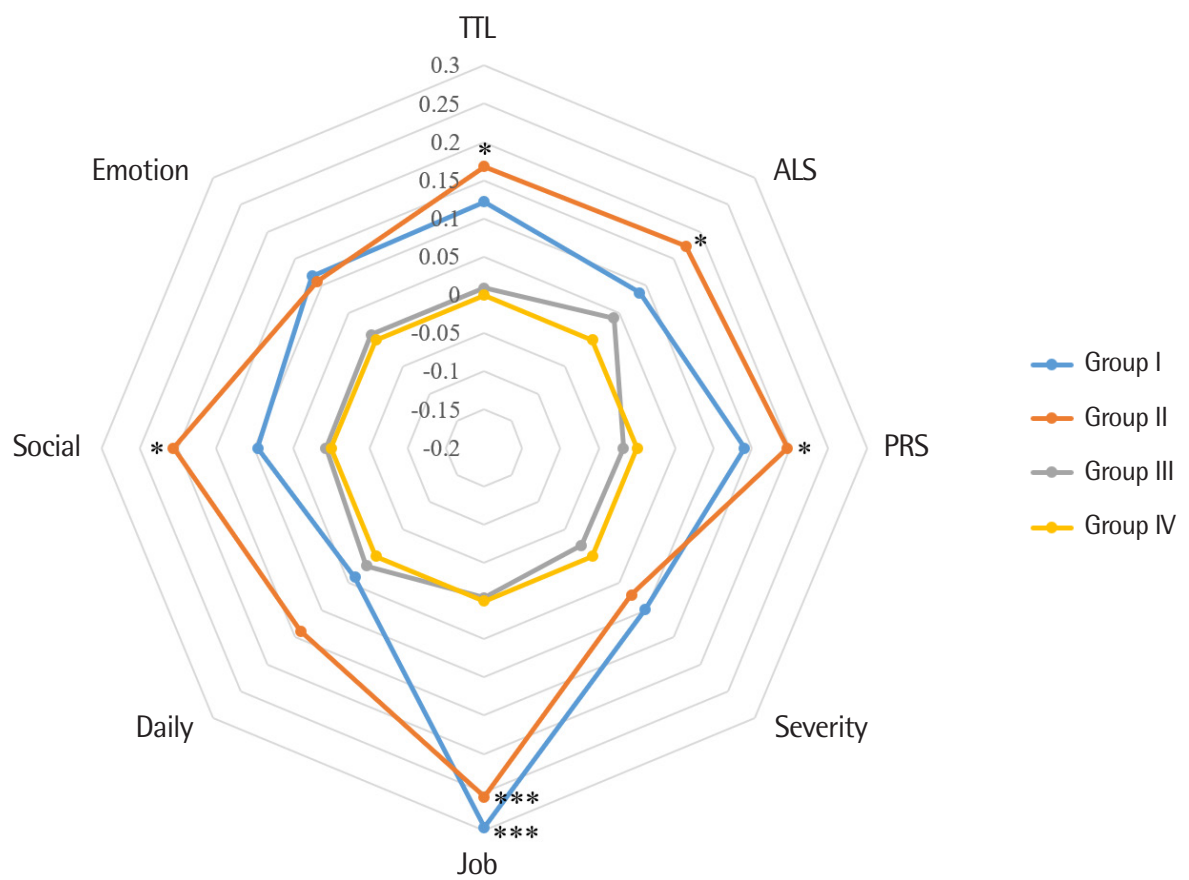

Figure 2. A radial plot of standardized Beta coefficients of the K-VAPP subscale scores according to the levels of professional voice use.

K-VAPP = Korean version of the Voice Activity and Participation Profile; group I= elite vocal performer group; group II= professional voice user group; group III= nonvocal professional group; group IV=non-vocal non-professional group; $T \mathrm{TL}=$ total score of the K-VAPP; $A L S=$ activity limitation score; PRS= participation restriction score.

${ }^{*} p<.00625,{ }^{* * *} p<.001$.

\section{연구결과}

BVFL 여부 및 직업적 음성사용 수준에 따른 K-VAPP의 각 하위 점수, 그리고 청지각적 평정의 결과인 $\mathrm{G}$ 평정치의 평균과 표준편차 가 Table 1 에 제시되어 있다. G의 경우 BVFL 여부에 따른 차이는 유 의하였으나 $(t=-34.027, p<.001)$, 일원분산분석을 통해 살펴 본 직 업적음성사용수준에 따른차이는 유의하지 않았다 $(F=.222, p=.881)$.

K-VAPP의 TTL, ALS, PRS 및 5 개의 모든 하위점수에 대한 회귀 분석을 시행한 결과, 모든 모형이 유의하였다. 각 회귀모형의 요약 이 Table 2에 제시되어 있다.

BVFL 여부, 성별, 중증도를 통제하였을 때 기준집단인 집단 IV 에 비교하였을 때 K-VAPP 점수의 유의한 차이를 보인 집단은 집 단 I과 집단 II였다(Table 3). 집단 IV에 비해 집단 I은 더 높은 Job 점수를 보였으며, 집단 II의 경우 TTL, ALS, PRS, Job, Social 점수 가 더 높았다. 집단 III은 집단 IV와 K-VAPP 점수에 있어 유의한 차이를 보이지 않았다. Figure 2는 각 하위점수별로 집단 I, II, III, $\mathrm{IV}$ 의 표준화 Beta 계수를 레이더망 그래프(radial graph)로 시각화 한 것이다.

\section{논의 및 결론}

본 연구에서는 음성장애의 중증도와 성별, BVFL 여부를 통제하 였을 때, 직업적 음성사용 수준에 따라 음성 활동 및 참여 프로파 일 점수에 차이가 있는지의 여부를 알아보고자 하였다. 그 결과 기 준 집단인 비직업적 비음성사용자에 비해 엘리트 음성사용자는 $\mathrm{Job}$ 점수가, 직업적 음성사용자는 K-VAPP의 하위점수인 직업 영역 (Job) 점수뿐만 아니라 총점(TTL), 활동제한점수(ALS), 참여제약 점수(PRS), 사회적 의사소통(Social) 영역점수가 더 높았다. 이는 흔 히 음성의 중요성이 더욱 클 것으로 생각되는 엘리트 음성사용자 뿐만 아니라 전문적 음성사용자 집단에서 더욱 크게 보고될 수 있 는 다양한 영역의 음성 활동의 제한이나참여의 제약을 중재 시 고 려하여야 한다는 점을 시사한다.

엘리트 음성사용자와 직업적 음성사용자가 기준집단에 비해 공 통되게 더욱 높은 활동제한과 참여제약을 보인 영역은 바로 직업 관련 영역이었다. 해당 영역의 문항들을 보다 구체적으로 살펴보 면, '현재의 목소리 문제 때문에 직장생활에 지장을 받는지, 직장일 에 대한 스트레스가 가중되는지'를 묻고 있으며, 나아가 이러한 문 제들로 인해 '지난 6개월 동안 실제로 직업을 바꿀 생각을 하거나 
앞으로의 경력에 관한 결정에 영향을 받은 적이 있는지'를 묻고 있 다(Lee et al., 2016). 물론 이러한 문항에서 비직업적 비음성사용자 에 비해 높은 점수를 보인 것은 다양한 전문적 음성사용 직군에서 더 높은 주관적 음성장애 정도가 나타났다고 보고한 선행연구 (Bassi et al., 2011; Cantor Cutiva \& Burdorf, 2014; Dassie-Leite et al., 2014; Dragone, 2011; Martinello et al., 2011; Natour et al., 2016; Piwowarczyk et al., 2012; Zambon et al., 2014)와 일치하지만, 문항 자체의 내용을 살펴보면 그리 놀랄만한 일은 아니다. 다만 주목할 만한 것은 중증도와 성별, 질환 여부 등을 통제하였음에도 불구하 고 이러한 경향이 명확하게 확인되었다는 사실이며, 이는 VHI를 이용한 Kim (2015)의 선행연구 결과와도 일맥상통하는 결과라 할 수 있다.

엘리트 음성사용자는 총점, 활동제한점수, 참여제약점수, 사회 적 의사소통 영역 점수에서 비직업적 비음성사용자와 유의한 점수 차이를 보이지 않았다. 이는 엘리트 음성사용자가 음성 문제로 인 해 더욱 가중된 음성 불편을 느끼는 경향이 직업적인 영역에 국한 되어 나타난다는 것을 시사한다. 이는 부분적으로는 음성을 이용 한 이들의 퍼포먼스 자체가 음성의 질 악화를 유발하는 것과 관련 된 것으로 보이며, 이러한 음성 변화는 단순한 음성위생교육만 가 지고는 쉽게 개선되지 않는 것으로 보고되었다(Rangarathnam, Paramby, \& McCullough, 2018). 특히 가수들의 경우 성악, 실용음 악, 판소리, 민요 등 가창의 장르에 따라 상이한 양상을 보일 수 있 으며, 경우에 따라서는 전문적인 가창 방법을 교정하는 데 언어재 활사보다는 발성교사(singing teacher)의 도움을 받아야 근본적인 해결을 할 수 있는 경우도 있다(Yoo, 2017). 예컨대 판소리의 경우 그 본질적인 특성상 서양음악 혹은 실용음악에 비해 거칠고 탁한 소리, 즉 탁성(濁聲)을 강조하여 맑은 ‘양성’보다는 더 탁한 ‘천구성’ 이나 거칠고 컬컬한 쉰 소리인 '수리성'을 선호한다(Hong, 2011). 스 페인의 민속 음악인 플라멩코(Flamenco) 가수에 대한 한 연구에서 는 플라멩코 가수가 성악가에 비해 가창 시 부적절한 발성 테크닉 을 더 많이 사용하고, 워밍업이 부족하며, 음성에 부정적인 영향을 주는 환경적 습관을 더 많이 보이는 것으로 보고되었다(García \& López, 2017). 본 연구의 집단 I에 속하는 대상자 중에서도 가장 많 은 비중을 차지한 대상자의 음악장르는 실용음악 $(58 \%)$ 이었으며, 이러한 특수성으로 말미암아 일상적인 생활에서의 음성 활동 및 참여보다는 직업 영역에서의 어려움에만 더욱 민감할 수 있는 것으 로 여겨진다.

그러나 사실 엘리트 음성사용자의 음성 문제는 직업적인 영역의 문제에 국한되지 않을 수 있다. 실제 성악가나 가수 등 엘리트 음성 사용자인 환자에서 일상 대화 시 과기능적인 발성 양상을 보임에도
불구하고 주관적으로는 '일상 대화에는 큰 불편함이 없으나 노래 에서 불편함이 크다'고 보고하는 임상 사례들이 적지 않다. 실제 가 수들의 VHI-10과 가창음성장애지수-10 (Singing Voice Handicap Index-10, SVHI-10) 점수를 비교한 연구에서는 대상자의 SVHI 점 수(평균 20.39점)가 VHI 점수(평균 12.10점)보다 유의하게 높았다 고 하였다(Renk, Sulica, Grossman, Georges, \& Murry, 2017). 이는 가수들이 기대와는 달리 발성의 해부생리학적 메커니즘에 대한 이 해도가 높지 않아서, 심지어 대상자의 약 $75 \%$ 가 발성 기제에 대한 본인들의 이해도가 낮다고 보고한 선행연구와도 일맥상통한다 (Sielska-Badurek et al., 2017) 따라서 이러한 간극에 대한 후속연구 를 통해 중재에 대한 시사점을 탐색해 볼 필요가 있을 것으로 여겨 진다. 앞서 언급한 선행연구(Sielska-Badurek et al., 2017)의 결과에 서 일정 기간의 기능적 발성 훈련 이후 발성 기능에 대한 이해도가 증진된 점 또한 이러한 필요성을 뒷받침한다. 또한 일상 대화 시의 잘못된 발성 습관 또한 전반적 음성의 상태에 큰 영향을 줄 수 있으 며, 언어재활사는 이들 엘리트 음성사용자의 가창 음성뿐만 아니 라 발화음성에도 관심을 가져야 한다는 점(Yoo, 2017)을 고려할 때, 이러한 연구의 필요성은 더욱 크다 할 수 있다.

직업 영역 점수 이외에도 직업적 음성사용자는 비직업적 비음성 사용자에 비해 총점, 활동제한점수, 참여제약점수, 사회적 의사소 통 영역 점수가 더 높았다. 이렇게 직업 이외에도 다른 영역, 특히 사 회적 의사소통 영역에서 더욱 큰 불편을 느끼고, 여러 음성 활동에 대한 '참여'에 이르기까지 더욱 큰 불편을 느끼는 것은 엘리트 음성 사용자가 주로 불편을 느끼는 발성의 양태(modality)가 '가창'(singing)으로서 일상 대화와는 다른 양태인 데 반해, 직업적 음성사용 자의 경우 직무상 음성사용의 양태가 사회적 의사소통과 동일한 구어를 활용한 '대화'인 것과 무관치 않아 보인다. 아울러 이는 음 성사용량이 많고 음성의 이상에 많은 영향을 받음에도 불구하고 스스로의 발성 기제 및 음성위생에 대한 이해도 혹은 실천 가능도 가 낮은 경향이 전문적 음성사용자 집단에서도 보고된다는 점과 도 관련이 있다. 예컨대 텔레마케터를 대상으로 한 선행연구에 따 르면 대상자의 약 $45 \%$ 가 음성 관련 증상을 보였는데, 이들 중 많은 수가 시끄러운 환경에서 음성을 사용하거나(40.51\%), 말할 때 목소 리에 힘을 주거나(16.46\%), 목을 자주 가다듬거나(10.13\%), 말할 때 중간에 잘 쉬지 않는 등 $(5 \%)$ 음성위생 관련 지식이 부족하거나, 음 성위생습관을 실천할 여건이 되지 않는다는 점을 시사하였다 (Fuentes-López, Fuente, \& Contreras, 2019).

요약하자면 엘리트 혹은 직업적 음성사용자가 유사한 정도의 음 성 문제를 보이더라도 더 큰 음성 활동 제한과 참여 제약을 느끼므 로, 이들을 대상으로 보다 적극적인 음성위생교육 및 음성치료를 
수행하여야 할 근거가 일부 마련되었다고 여겨진다. 또한 기존의 설 문지를 통해서는 알 수 없었던 음성 활동 제한이나참여 제약을 개 별적으로 살펴보았다는 데서 연구의 의의를 찾을 수 있다. 아울러 본 연구에서 확인되었듯 엘리트 음성사용자 혹은 직업적 음성사용 자는 음성에 문제가 생겼을 때 더욱 큰 음성 활동 제한 혹은 참여 제약을 느낄 수 있다는 점을 고려할 때, 건강한 음성을 가진 상태에 서 종합적인 음성평가를 사전에 시행해 두어 추후 혹여 음성 문제 를 경험할 때 적절한 해석을 위한 준거 자료로 활용할 필요성(Choi et al., 2013)이 더욱 타당성을 얻었다고 할 수 있다.

다만 본 연구에서는 설문결과에 대한 영향요인이 될 수 있는 연 령을 통제하고 직업에 따른 원활한 비교를 위해 60 세 이상의 대상 자는 많은 수를 포함하지는 못하였으며, 유사한 직업 가운데에서 도 서로 상이한 음성사용 패턴을 보일 수 있는 경우들을 세밀하게 고려하지는 못했다는 한계가 있다. 예컨대 같은 교사나 강사라 할 지라도 주당 강의시간 수에 따라 음성 활동 제한이나 참여 제약을 상이하게 느낄 수 있다. 한 선행연구에서는 15년 이상 장기간 강의 를 하거나, 주당 15 회 이상 수업을 하는 것이 교사의 음성장애 위험 요인이라고 보고하였다(Bolbol, Zalat, Hammam, \& Elnakeb, 2017). 따라서 이와 같은 방식으로 동일 직종 내에서 음성 활동 제한 및 참 여 제약을 가중시킬 수 있는 위험 요인을 탐색하는 후속연구를 진 행한다면, 대상자의 각 직업 특성에 맞는 적절한 음성사용 패턴을 제시하는 개별화된 치료의 근거를 마련할 수 있는 흥미로운 주제 가 될 것으로 여겨진다.

\section{REFERENCES}

Bassi, I. B., Assunção, A. Á., de Medeiros, A. M., de Menezes, L. N., Teixeira, L. C., \& Gama, A. C. C. (2011). Quality of life, self-perceived dysphonia, and diagnosed dysphonia through clinical tests in teachers. Journal of Voice, 25(2), 192-201.

Bolbol, S. A., Zalat, M. M., Hammam, R. A., \& Elnakeb, N. L. (2017). Risk factors of voice disorders and impact of vocal hygiene awareness program among teachers in public schools in Egypt. Journal of Voice, 31(2), 251.e9251.e16.

Boone, D. R., McFarlane, S. C., Von Berg, S. L., \& Zraick, R. I. (2014). The voice and voice therapy (9th ed.). Boston, MA: Pearson.

Byeon, H., \& Lee, Y. (2010). Prevalence and risk factors of benign laryngeal lesions in the adult population. Korean Journal of Communication \& Disorders, 15(4), 648-656.

Cantor Cutiva, L. C., \& Burdorf, A. (2014). Factors associated with voice-re- lated quality of life among teachers with voice complaints. Journal of Communication Disorders, 52, 134-142.

Choi, J. S., Lim, J. Y., \& Kim, Y. M. (2013). The characteristics of the professional voice users. Journal of the Korean Society of Laryngology, Phoniatrics and Logopedics, 24(1), 18-22.

Choi, S. H. (2013). Speech-language pathologists' voice assessment and voice therapy practices: a survey for standard clinical guideline and evidencebased practice. Communication Sciences \& Disorders, 18(4), 473-485.

Dassie-Leite, A. P., Delazeri, S., Baldissarelli, B., \& Weber, J. (2014). Vocal selfassessment: relation with the type of instrument, gender, age, and profession in individuals without vocal complaints. CoDAS, 26(6), 531-534.

Dragone, M. L. S. (2011). Voice activity and participation profile presenting coordinates for readjustment of preventive action of educators. Folia Phoniatrica et Logopaedica, 63(1), 49-54.

Eadie, T. L. (2003). The ICF: A proposed framework for comprehensive rehabilitation of individuals who use alaryngeal speech. American Journal of Speech Language Pathology, 12(2), 189-197.

Faul, F., Erdfelder, E., Buchner, A., \& Lang, A. G. (2009). Statistical power analyses using $\mathrm{G}^{\star}$ Power 3.1: Tests for correlation and regression analyses. Behavior Research Methods, 41(4), 1149-1160.

Fontan, L., Fraval, M., Michon, A., Déjean, S., \& Welby-Gieusse, M. (2017). Vocal problems in sports and fitness instructors: a study of prevalence, risk factors, and need for prevention in France. Journal of Voice, 31(2), 261.e33-261.e38.

Fuentes-López, E., Fuente, A., \& Contreras, K. V. (2019). Inadequate vocal hygiene habits associated with the presence of self-reported voice symptoms in telemarketers. Logopedics Phoniatrics Vocology, 44(3), 105-114.

García, M. G., \& López, J. M. (2017). Voice habits and behaviors: voice care among flamenco singers. Journal of Voice, 31(2), 246.e11-246.e19.

Hirano, M. (1981). Clinical examination of voice. New York, NY: Springer.

Hong, K. H. (2011). The Vocalization for Korean Traditional Song. Journal of the Korean Society of Laryngology, Phoniatrics and Logopedics, 22(2), 111114.

Kim, H. (2012). Neurogenic speech-language disorders. Seoul: Sigmapress.

Kim, J. (2015). Comparison of self-reporting voice evaluations between professional and non-professional voice users with voice disorders by severity and type. Phonetics and Speech Sciences, 7(4), 67-76.

Kim, J. O., Lim, S. E., Park, S. Y., Choi, S. H., Choi, J. N., \& Choi, H. S. (2007). Validity and reliability of Korean-version of voice handicap index and voicerelated quality of life. Speech Sciences, 14(3), 111-125. 
Kleemola, L., Helminen, M., Rorarius, E., Sihvo, M., \& Isotalo, E. (2011). Twelvemonth clinical follow-up study of voice patients' recovery using the Voice Activity and Participation Profile (VAPP). Journal of Voice, 25(5), e245e254.

Koufman, J. A., \& Isaacson, G. (1991). The spectrum of vocal dysfunction. Otolaryngologic Clinics of North America, 24(5), 985-988.

Kwon, T. K., \& Kim, M. S. (2015). Current standpoints on the pathophysiology of benign vocal fold lesions. Journal of the Korean Society of Laryngology, Phoniatrics and Logopedics, 26(2), 91-93.

Lee, S. J., Choi, H. S., \& Kim, H. (2019). A comparison of voice activity and participation profiles among etiological groups. Journal of Voice, 33(5), 804.e5-804.e12.

Lee, S. J., Choi, H. S., Kim, H., Byeon, H. K., Lim, S. E., \& Yang, M. K. (2016). Korean version of the Voice Activity and Participation Profile (K-VAPP): a validation study. Communication Sciences \& Disorders, 21(4), 695-708.

Lee, S. J., Lim, S. E., \& Choi, H. S. (2017). Responsiveness of the Korean version of the Voice Activity and Participation Profile (K-VAPP) after surgical intervention. Communication Sciences \& Disorders, 22(2), 379-390.

Lee, S. J., Lim, S. E., Lim, J. Y., \& Choi, H. S. (2018). A comparison among repeated measures of the voicing efficiency protocol in the aerodynamic assessment. Communication Sciences \& Disorders, 23(3), 755-764.

Lyberg-Åhlander, V., Rydell, R., \& Löfqvist, A. (2012). How do teachers with self-reported voice problems differ from their peers with self-reported voice health? Journal of Voice, 26(4), e149-e161.

Ma, E. P. M., \& Yiu, E. M. L. (2001). Voice activity and participation profile: assessing the impact of voice disorders on daily activities. Journal of Speech, Language, and Hearing Research, 44(3), 511-524.

Ma, E. P. M., \& Yiu, E. M. L. (2006). Multiparametric evaluation of dysphonic severity. Journal of Voice, 20(3), 380-390.

Ma, E. P. M., \& Yiu, E. M. L. (2011). Handbook of voice assessments. San Diego, CA: Plural Pub.

Martinello, J. G., Lauris, J. R. P., \& Brasolotto, A. G. (2011). Psychometric assessments of life quality and voice for teachers within the municipal system, in Bauru, SP, Brazil. Journal of Applied Oral Science, 19(6), 573-578.

Meulenbroek, L. F., Thomas, G., Kooijman, P. G., \& de Jong, F. I. (2010). Biopsychosocial impact of the voice in relation to the psychological features in female student teachers. Journal of Psychosomatic Research, 68(4), 379384.

Natour, Y. S., Sartawi, A. M., Al Muhairy, O., Efthymiou, E., \& Marie, B. S.
(2016). Emirati teachers' perceptions of voice handicap. Journal of Voice, 30(3), 378.e13-378.e20.

Piwowarczyk, T. C., Oliveira, G., Lourenço, L., \& Behlau, M. (2012). Vocal symptoms, voice activity, and participation profile and professional performance of call center operators. Journal of Voice, 26(2), 194-200.

Rangarathnam, B., Paramby, T., \& McCullough, G. H. (2018). “Prologues to a bad voice": effect of vocal hygiene knowledge and training on voice quality following stage performance. Journal of Voice, 32(3), 300-306.

Renk, E., Sulica, L., Grossman, C., Georges, J., \& Murry, T. (2017). VHI-10 and SVHI-10 differences in singers' self-perception of dysphonia severity. Journal of Voice, 31(3), 383.e1-383.e4.

Rosow, D. E., Szczupak, M., Saint-Victor, S., Gerhard, J. D., DuPont, C., \& Lo, K. (2016). The economic impact of vocal attrition in public school teachers in Miami-Dade County. The Laryngoscope, 126(3), 665-671.

Ruotsalainen, J. H., Sellman, J., Lehto, L., Isotalo, L. K., \& Verbeek, J. H. (2007). Interventions for preventing voice disorders in adults. Cochrane Database of Systematic Reviews, (4), CD006372.

Sielska-Badurek, E., Osuch-Wójcikiewicz, E., Sobol, M., Kazanecka, E., Rzepakowska, A., \& Niemczyk, K. (2017). Combined functional voice therapy in singers with muscle tension dysphonia in singing. Journal of Voice, 31(4), 509.e23-209.e31.

Thomas, G., Kooijman, P. G., Donders, A. R. T., Cremers, C. W., \& de Jong, F. I. (2007). The voice handicap of student-teachers and risk factors perceived to have a negative influence on the voice. Journal of Voice, 21(3), 325-336.

Van Lierde, K. M., D’haeseleer, E., Wuyts, F. L., De Ley, S., Geldof, R., De Vuyst, J., \& Sofie, C. (2010). The objective vocal quality, vocal risk factors, vocal complaints, and corporal pain in Dutch female students training to be speech-language pathologists during the 4 years of study. Journal of Voice, 24(5), 592-598.

Verdolini, K., \& Ramig, L. O. (2001). Occupational risks for voice problems. Logopedics Phoniatrics Vocology, 26(1), 37-46.

Yoo, J. Y. (2017). The SLP's perspectives for the vocal elites and singing voice. Journal of the Korean Society of Laryngology, Phoniatrics and Logopedics, 28(1), 11-13.

Yun, Y. S., Kim, H., Son, Y. I., \& Choi, H. S. (2008). Validation of the Korean Voice Handicap Index (K-VHI) and the clinical usefulness of Korean VHI10. Korean Journal of Communication Disorders, 13(2), 216-241.

Zambon, F., Moreti, F., \& Behlau, M. (2014). Coping strategies in teachers with vocal complaint. Journal of Voice, 28(3), 341-348. 


\section{국문초록}

\section{직업적 음성사용 패턴에 따른 음성 활동 및 참여 프로파일 비교}

이승진 ${ }^{1,2} \cdot$ 임성은 $^{3} \cdot$ 최홍식 $2,4 \cdot$ 임재열1,2

1연세대학교 의과대학 이비인후과학교실, ${ }^{2}$ 강남세브란스병원 이비인후과 후두음성언어의학연구소, ${ }^{3}$ 강남세브란스병원 이비인후과 음성언어치료실, ${ }^{4}$ 하나이비인후과병원

배경 및 목적: 본 연구에서는 양성 성대점막 질환(BVFL) 여부, 성별, 음성장애의 중증도를 통제하였을 때 직업적 음성사용 수준에 따 라 음성 활동 제한 혹은 음성 활동 제약에 차이가 있는지의 여부를 알아보고자 하였다. 방법: 연구대상은 BVFL로 진단된 환자군 120 명과 정상 대조군 120 명이었다. 각 집단은 음성사용 수준에 따라 엘리트 음성사용자(I), 직업적 음성사용자(II), 직업적 비음성사용자 (III), 비직업적 비음성사용자(IV) 각 30명으로 구성되었다. 심리측정적 평가로는 K-VAPP를, 청지각 평가로는 GRBAS를 시행하였다. K-VAPP 총점, 활동제한점수(ALS), 참여제약점수(PRS), 각 하위영역 점수(5개)를 종속변수로 하여 다중회귀분석을 시행하였다. 결과: $\mathrm{BVFL}$ 여부, 성별, 중증도(G)를 통제하였을 때, 기준 집단(IV)에 비해 집단 I은 총점, PRS, 중증도 인식 점수, 직업 영향 점수, 감정 영향 점수가 높았으며, 집단 II는 총점, ALS, PRS, 직업 영향 점수, 사회적 의사소통 영향 점수가 높았다. 반면, 집단 III은 기준 집단과 유의한 차이를 보이지 않았다. 논의 및 결론: 직업적 음성사용 수준에 따른 이러한 차이는 엘리트 음성사용자에 비해 직업적 음성사용자가 겪 는 음성 문제가 결코 작지 않다는 것을 시사하며, 이를 음성치료 계획 수립에 적극적으로 반영할 필요가 있을 것으로 여겨진다.

핵심어: 음성 활동 및 참여 프로파일, 직업적 음성사용, 환자보고 결과 측정, 국제기능장애건강분류, 음성장애

본 연구는 2018년 대한민국 교육부와 한국연구재단의 지원을 받아수행된 연구임(No. NRF-2018S1A5A2A02069988).

\section{참고문헌}

권택균, 김민수(2015). 양성 성대 질환의 병태생리에 관한 최신지견. 대한후두음성언어의학회지, 26(2), 91-93.

김재옥(2015). 음성장애가 있는 직업적 음성사용자와 비직업적 음성사용자의 음성장애 중증도와 유형에 따른 자기보고식 음성평가 차이. 말소리와 음성과학, 7(4), 67-76.

김재옥, 임성은, 박선영, 최성희, 최재남, 최홍식(2007). 한국어판 음성장애지수와 음성관련 삶의 질의 타당도 및 신뢰도 연구. 음성과학, 14(3), 111-

125 .

김향희(2012). 신경언어장애. 서울: 시그마프레스.

변해원, 이윤환(2010). 후두양성점막질환의 유병률과 인구사회학 및 건강 관련 요인. 언어청각장애연구, 15(4), 648-656.

유재연(2017). 가수 음성에 대한 언어재활사의 관점. 대한후두음성언어의학회지, 28(1), 11-13.

윤영선, 김향희, 손영익, 최홍식(2008). 한국어판 음성장애지수(Voice Handicap Index, VHI)의 타당도 및 VHI-10의 임상적 유용성. 언어청각장애연

구, 13(2), 216-241.

이승진, 임성은, 임재열, 최홍식(2018). 공기역학적 평가에서 음성 효율성 프로토콜의 반복 측정치 비교. Communication Sciences \& Disorders, 23(3), 755-764.

이승진, 임성은, 최홍식(2017). 수술적 중재 후음성 활동 및 참여 프로파일-한국판(K-VAPP)의 반응도 연구. Communication Sciences \& Disorders, 22(2), 379-390.

이승진, 최홍식, 김향희, 변형권, 임성은, 양민교(2016). 음성 활동 및 참여 프로파일-한국판(K-VAPP): 타당성 검증 연구. Communication Sciences \&

Disorders, 21(4), 695-708.

최성희(2013). 음성언어재활사의 음성평가와 음성치료의 임상실제: 표준 임상지침과 증거기반중재를 위한 설문조사. Communication Sciences \&

Disorders, 18(4), 473-485. 
최정석, 임재열, 김영모(2013). 직업적 음성사용자의 특징. 대한후두음성언어의학회지, 24(1), 18-22.

홍기환(2011). 국악(판소리) 발성법. 대한음성언어의학회지, 22(2), 111-114.

\section{ORCID}

이승진(https://orcid.org/0000-0001-6200-0004); 임성은(https://orcid.org/0000-0003-4581-6356);

최홍식(https://orcid.org/0000-0002-9612-1303); 임재열(https://orcid.org/0000-0002-9757-6414) 